\title{
In Planta Genetic Transformation of Mungbean (Vigna radiata (L.) Wilczek) with Marker Gene
}

\author{
Mohammad Mahmood Hasan, Sujay Kumar Bhajan, M. Imdadul Hoque, \\ R. H. Sarker and Mohammad Nurul Islam* \\ Plant Breeding and Biotechnology Laboratory, Department of Botany, University of Dhaka, \\ Dhaka-1000, Bangladesh
}

Key words: Mungbean, In planta transformation, Gus gene, pBI121, Recalcitrant crop

\begin{abstract}
In genetic improvement of mungbean much success has not been achieved due to its recalcitrant nature towards in vitro regeneration. An attempt was made to develop an Agrobacterium-mediated in planta genetic transformation protocol for a locally grown mungbean variety BARI Mung-3 using a screenable marker gene. Two minutes of vacuum infiltration followed by 60 minutes of incubation period in Agrobacterium suspension of Winans' AB medium containing wounded tobacco leaf extract was found most suitable towards genetic transformation in pricked de-coated half seed explants. An optical density ( $\mathrm{OD}_{600}$ ) of 0.7 was found most effective for transient gus gene expression. Chimeric GUS expression was observed in the root and leaf tissues from the successfully transformed plantlets obtained through in planta transformation. This methodology of genetic transformation was found more suitable, easier and less time consuming than tissue culture based genetic transformation, which may be used for the genetic improvement of mungbean.
\end{abstract}

\section{Introduction}

Mungbean (Vigna radiata (L.) Wilczek) also known as green gram is a pulse crop mainly cultivated in south and south-east Asia, but the cultivation has also been extended to parts of USA, Canada, Australia and Ethiopia (Schafleitner et al. 2015). It is one of the major sources of vegetable protein (25\%). It is also rich in carbohydrate, fat and fibre which made it an excellent supplement of cereal diets. Moreover, the early ripening characteristic, high nutritional value and easy digestibility have made its cultivation more popular (Yadav et al. 2012). In Bangladesh mungbean is the third most cultivated

*Author for correspondence: <m.nurul@du.ac.bd>.

DOI: https://doi.org/10.3329/ptcb.v29i2.44513 
pulse crop with highest market value. Though it has high demand the production rate is far below. As a result, Bangladesh has to import a large amount of mungbean from its neighbouring countries (Bhajan et al. 2019).

The production of mungbean is further hindered by various abiotic (drought, temperature, water logging and salt) and biotic stress factors. Among biotic factors Mungbean Yellow Mosaic Virus (MYMV) is the most devastating one since it may result more than 50\% yield loss (Vir et al. 2016, Islam and Islam 2010). Conventional breeding for genetic improvement of mungbean reported being a hurdle due to the lack of genetic variability as it is a self-pollinated crop and absence of resistant genes in the germplasm. Moreover, failure of pollen tube to penetrate stigma, failure in pod formation, embryo abortion lead to unsuccessful intervarietal hybridization (Vir et al. 2016, Yadav et al. 2010). Biotechnological approaches could help breeders to overcome such issues for the genetic improvement of mungbean since it allows integrating gene $/ s$ from distantly related organisms. However, a reproducible and efficient in vitro regeneration protocol is a pre-requisite of plant genetic transformation (Mohanty and Sagare 2015). Though successful in vitro regeneration of mungbean plantlets were reported from various explants, for instance, cotyledonary nodes (Mohanty and Sagare 2015, Vats et al. 2014, Himabindu et al. 2014), cotyledon, hypocotyl, root and shoot tip (Khatun et al. 2008), double cotyledonary node (Yadav et al. 2010), decapitated mature embryo (Hoque et al. 2007), cotyledon attached decapitated embryo (Bhajan et al. 2019) it is still considered as a recalcitrant plant towards tissue culture particularly in case of developing healthy and viable root system. Development of Agrobacterium-mediated genetic transformation protocol has also achieved very little success in mungbean as it is not amenable towards genetic modification (Vir et al. 2016, Dewir et al. 2016). Till date, very little success has been achieved towards the genetic modification of mungbean and most of them are confined with reporter gene (e.g. gus) (Bhajan et al. 2019, Yadav et al. 2012, Islam and Islam 2010, Tazeen and Mirza 2004, Jaiwal et al. 2001). There are some reports of successful development of transgenic mungbean with alien gene (Baloda and Madanpotra 2017, Kumar et al. 2017, Sahoo et al. 2016, Vijayan and Kirti 2012, Saini et al. 2007) but the success rate is reported to be between 1 and $2 \%$.

Considering such recalcitrant nature of the mungbean plants towards in vitro regeneration, a tissue culture-independent genetic transformation method called in planta genetic transformation has been conceptualized. Such a method is quicker, simpler, cheaper, more efficient and somaclonal variation free (Rao et al. 2008, Niazian et al. 2017). Hence, attempts have been made to develop an Agrobacterium-mediated in planta genetic transformation protocol in a locally grown Bangladeshi mungbean variety, namely BARI Mung-3 using a screenable marker gene called "gus"gene.

\section{Materials and Methods}

Seeds of BARI Mung-3 (Pragati) developed and released by Bangladesh Agricultural Research Institute (BARI) on 1996 was used for in planta transformation. The seeds were 
first washed with tap water and then surface sterilized with $70 \%$ alcohol $(30 \mathrm{sec})$ and washed again with autoclaved distilled water immediately. Seeds were dipped in $0.1 \%$ $\mathrm{HgCl}_{2}$ solution (8 - $10 \mathrm{~min}$.) followed by 3 - 4 times wash in distilled water. Then the seeds were soaked overnight in autoclaved distilled water for germination in a dark chamber. The germinated seeds were then de-coated, and one of the cotyledons was removed carefully so that, the embryo remain attached with one cotyledon (half seed explants). For making injury into the explants, $0.5 \mathrm{ml}$ insulin disposable syringe was used. Two to three pricks were made at the embryonal axis of the half seed explants to facilitate the transformation.

Agrobacterium tumefaciens strain LBA4404 (plasmid) was used harbouring in plant transformation vector of $\mathrm{pBI} 121$. The T-DNA portion between the right border (RB) and left border (LB) of the plasmid contains a gus gene flanked by CaMV 35S promoter and NOS terminator. The plasmid also has a kanamycin resistant gene (nptII) in the T-DNA segment which is driven by NOS promoter and terminated by NOS terminator (Fig. 1).

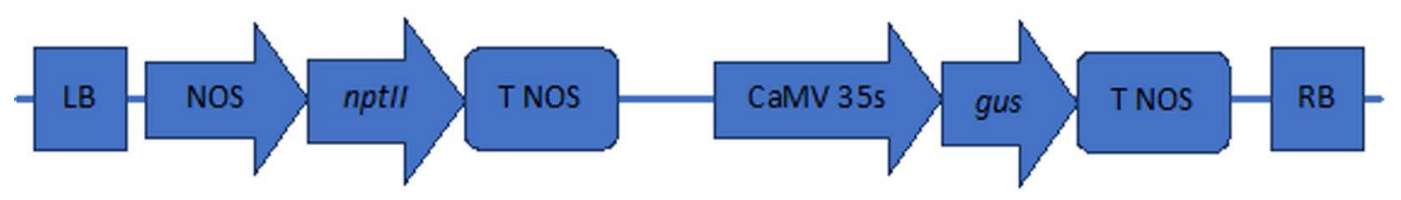

Fig. 1. Diagrammatic representation of the T-DNA region of the pBI121 plasmid.

The A. tumefaciens was grown overnight in $10 \mathrm{ml} \mathrm{YMB}$ medium supplemented with $50 \mathrm{mg} /$ kanamycin, $25 \mathrm{mg} / \mathrm{streptomycin}$ and $25 \mathrm{mg} /$ rifampicin at $28^{\circ} \mathrm{C}$ in a rotary shaker at $250 \mathrm{rpm}$. On next day 1\% culture was inoculated in $40 \mathrm{ml} \mathrm{YMB}$ medium and grown overnight in the above-mentioned conditions for antibiotic selections. This bacterial suspension was used directly to infect the explants at various optical densities $\left(\mathrm{OD}_{600}\right)$ to find out the optimum $\mathrm{OD}_{600}$ towards best transformation efficiency. The overnight cultured Agrobacterium in YMB medium was pellet downed by centrifugation at $5000 \mathrm{rpm}$ for $10 \mathrm{~min}$ when the $\mathrm{OD}_{600}$ was 0.7 . The pellet was re-suspended in Winans' $\mathrm{AB}$ medium (Winans et al. 1988) containing required antibiotics as mentioned earlier, followed by culture in an orbital shaker for around $18 \mathrm{hrs}$. For the induction of vir gene activity, fresh tobacco leaf extract $(8 \mathrm{~g}$ of leaf was crushed in $8 \mathrm{ml}$ of autoclaved distilled water) was added to the medium $5 \mathrm{hrs}$ before the infection.

The de-coated half seed explants were injured at the point with a sterile $0.5 \mathrm{ml}$ insulin disposable syringe and incubated in bacterial suspension in $\mathrm{AB}$ medium for different incubation periods $(15,30,45,60$ and $120 \mathrm{~min})$. Before incubation, the bacterial suspension containing the half seed explants were subjected to vacuum infiltration for different periods of time. After incubation, the explants were washed three times with autoclaved distilled water followed by $10 \mathrm{~min}$ of antibiotic wash $(300 \mathrm{mg} /$ carbenicillin solution). After that explants were soaked dried on filter paper and then inoculated to half strength of MS, devoid of any kind of hormone and let them grow in tissue culture 
growth room at $25^{\circ} \mathrm{C}$ and $16 \mathrm{hrs}$ of light and $8 \mathrm{hrs}$ of dark. After the formation of the healthy root system, the plantlets were washed with autoclaved distilled water to remove the adhering medium and then transferred to plastic pots containing autoclaved soil and hardened in tissue culture growth room conditions as mentioned earlier. The plants were transferred to larger earthen pots containing autoclaved soil.

The activity of gus gene expression was evaluated through GUS histochemical assay. Agrobacterium infected explants and different tissues (leaf, stem and root) were treated with $\mathrm{X}$-gluc at $37^{\circ} \mathrm{C}$ for $72 \mathrm{hrs}$. Afterwards, the tissues were kept in $100 \%$ ethanol to bleach the chlorophyll contents. Some tissues were observed directly with naked eye and stereomicroscope (Nikon SMZ1000). Some tissues were hydrolyzed with $1 \mathrm{~N} \mathrm{NaOH}$ solution in a glass vessel at $65^{\circ} \mathrm{C}$ for $15-20 \mathrm{~min}$ until the tissues become soft enough to be macerated. The tissues were placed on the microscopic glass slide (with $50 \% \mathrm{v} / \mathrm{v}$ glycerol) and pressed with a cover slip to macerate the cells. The cells were observed under Nikon ECLIPSE 50i compound light microscope (Nikon, Japan).

\section{Results and Discussion}

The plant material (BARI Mung-3) used in this study was chosen because it has high yielding capacity (1000 to $1100 \mathrm{~kg}$ ha), less cooking time (14 to $17 \mathrm{~min}$ ) and $19-21 \%$ protein content but it has been reported to be susceptible to disease incidences like Cercospora leaf spot and MYMV (Faruq and Islam 2010). The de-coated half seeds are the best option for in planta transformation of pulse crops (Kapildev et al. 2016).

The efficiency of the gus gene transformation into plant tissue was evaluated through GUS histochemical assay (Jefferson et al. 1987) and the samples were chosen randomly. The successfully transformed cells developed blue colour within the cells of the half seed explants (Fig. 2), leaves, and root cells (Figs 3, 4). However, in most of the cases the expression pattern of GUS was found chimeric in nature. On the other hand, non-transformed tissues failed to develop blue colour in GUS histochemical assay. Such chimeric expression of gene is considered as a disadvantage in the in planta transformation method (Niazian et al. 2017). In order to eliminate non-transformed and chimeric transformed plants in case of in planta transformation BASTA ${ }^{\circ}$ selection is proven to be most effective (Kapildev et al. 2016, Mayavan et al. 2015, Mayavan et al. 2013). In the present study such selection method was not used due to the unavailability of genetic construct with BASTA® resistant gene. Another study suggested that though $\mathrm{T}_{0}$ generation showed chimeric expression of gus gene in $\mathrm{T}_{1}$ generation the expression pattern becomes stable (Yellisetty et al. 2015).

To find out the impact of optical density, the explants were subjected to Agrobacterium culture of different optical densities at $600 \mathrm{~nm}$ (OD600) for $30 \mathrm{~min}$ followed by GUS histochemical assay and OD600 at 0.7 was found to be most effective (Table 1). The transformation efficiency was found to be increased with the $\mathrm{OD}_{600}$ but up to a certain point. Optical density over 0.7 was found to decrease the transformation efficiency. 

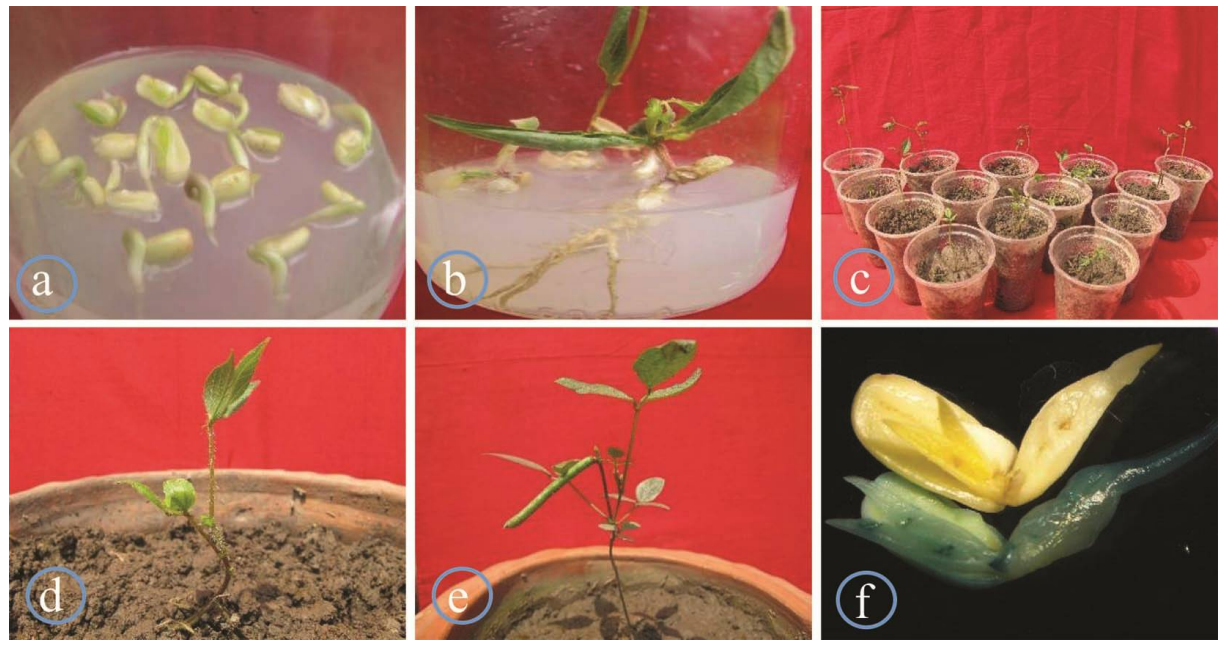

Fig. 2. In planta genetic transformation in BARI Mung-3. (a) Half seed explants on half strength MS, (b) well rooted in vitro germinated plants on half strength MS, (c) plants transferred to plastic pots, (d) hardened plant on earthen pot, (e) In vivo pod formation of the transformed plant and (f) successfully transformed half seed explants showing positive response along with control explants showing negative response in GUS histochemical assay.
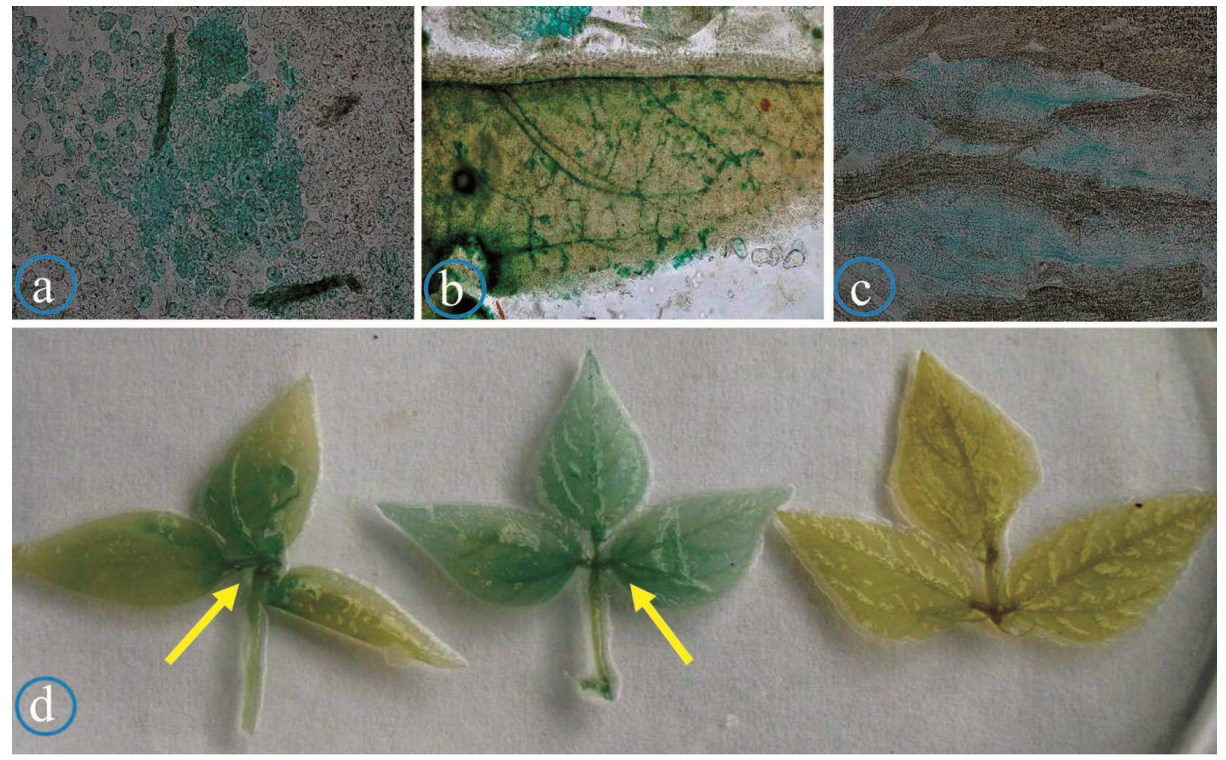

Fig. 3. GUS histochemical assay of the tissues of transformed mungbean plantlet. (a) Macerated cells of cotyledon, (b) macerated cells of plumule, (c) macerated cells of radicle tissues of half seed explants showing GUS positive response, (d) leaf of the transformed plants showing histochemical localization of GUS expression (blue colour) along with control showing no GUS expression. 

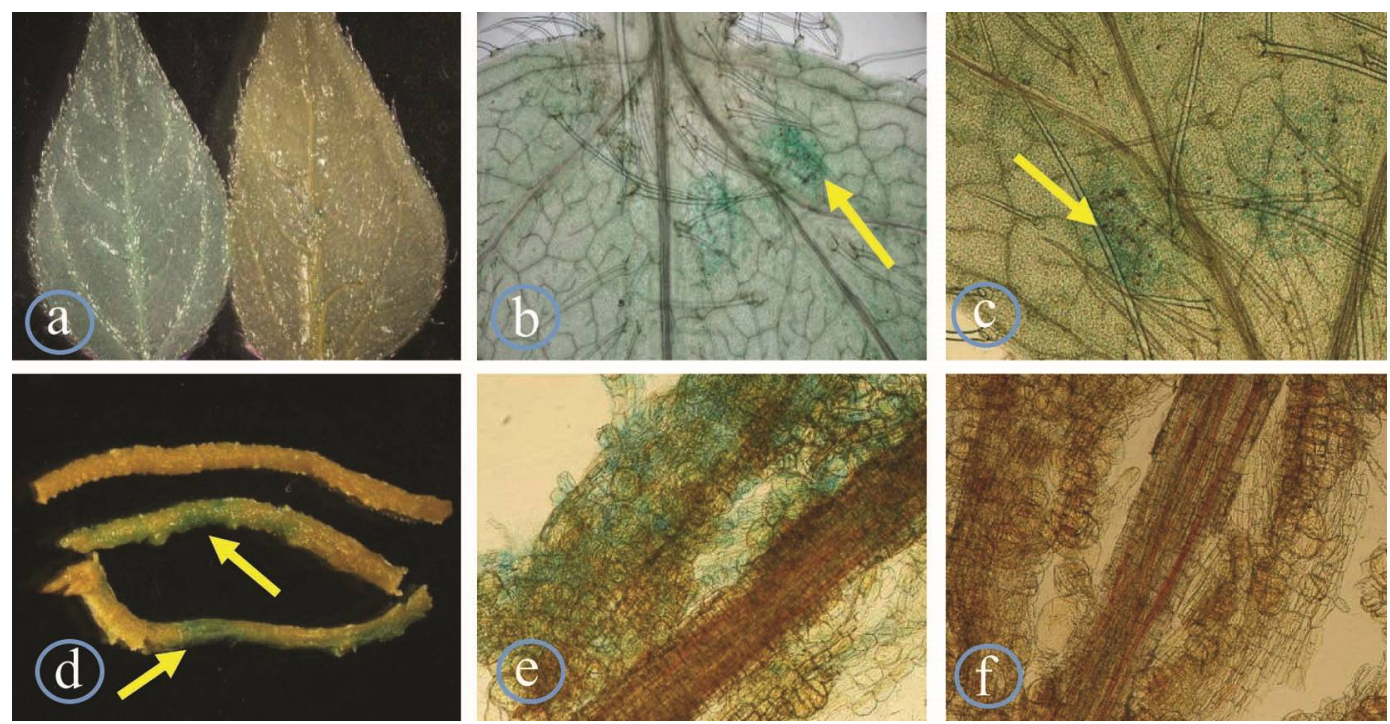

Fig. 4. Chimerical expression of gus gene in leaf and root tissue of the successfully transformed plants. (a) Stereomicroscopic view of the transformed leaf with control one, $(b, c)$ light microscopic view of the regions showing GUS positive expression, (d) GUS positive expression in the transformed roots, control root showing negative GUS expression, (e) macerated cells of root tissue from transformed plant showing GUS positive response, (f) macerated cells of root tissue from control plant showing GUS negative response.

Table 1. Impact of the optical density of the Agrobacterium culture towards genetic transformation efficiency.

\begin{tabular}{cc}
\hline Optical density $\left(\mathrm{OD}_{600}\right)$ & Av. GUS positive explants \\
\hline 0.4 & $2.67 \pm 0.58$ \\
0.5 & $5.30 \pm 1.53$ \\
0.6 & $6.67 \pm 1.15$ \\
0.7 & $11.00 \pm 1.00$ \\
0.8 & $8.67 \pm 1.15$ \\
0.9 & $8.33 \pm 1.52$ \\
1.0 & $7.33 \pm 1.15$ \\
\hline
\end{tabular}

The genetic transformation efficacy also depends on the incubation period of the explants in Agrobacterium suspension, but long-time incubation leads to browning of the cells and the tissues become necrotic (Keshamma et al. 2008). The impact of incubation period was found to have a direct impact over the transformation efficiency. It was observed that, the transformation efficiency increases with the duration of incubation of the explants in the bacterial suspension (Table 2). But long-time exposure to the bacterial suspension caused softening of the cells and breaking during handling of the explants 
that led to reduced capacity of further growth of the plants. Considering all these facts, an incubation period of $60 \mathrm{~min}$ was found suitable in the current study. Though there is no report of in planta genetic transformation in mungbean various tissue culture-based protocols reported various incubation period to be most efficient, for instance $45 \mathrm{~min}$ for cotyledon attached with embryonal axis (CAEA) (Islam and Islam 2010), $30 \mathrm{~min}$ for cotyledonary node explants (Sahoo et al. 2016), $15 \mathrm{~min}$ for double cotyledonary node explants (DCN) (Yadav et al. 2012). It is also worth to mention that the Agrobacterium strain and the plasmid used in these studies were different from other studies which is another reason behind achieving highest efficiency of genetic transformation for different incubation period.

Table 2. Impact of incubation period on genetic transformation efficiency.

\begin{tabular}{lccc}
\hline $\begin{array}{l}\text { Incubation period } \\
(\mathrm{min})\end{array}$ & $\begin{array}{c}\text { No. of explants } \\
\text { assayed }\end{array}$ & $\begin{array}{c}\text { No. of explants } \\
\text { showed a positive } \\
\text { response }\end{array}$ & $\begin{array}{c}\text { Percentage of GUS } \\
\text { positive explants }\end{array}$ \\
\hline 15 & 75 & 7 & 9.33 \\
30 & 75 & 15 & 20 \\
45 & 75 & 18 & 24 \\
60 & 75 & 24 & 32 \\
120 & 75 & 30 & 40 \\
\hline
\end{tabular}

Addition of tobacco leaf extract in the Agrobacterium suspension is reported to increase T-DNA transfer efficacy (Samarajeewa et al. 2012, Rao et al. 2008) since various phenolic compounds released from wounded tissue is required for vir gene induction and it is found more effective than adding a single phenolic compounds such as acetosyringone (Cheng et al. 1996). Ti-plasmid bearing cells grow remarkably slower in Winans' AB medium (Winans et al. 1988) due to phosphorus limitation but this medium results in high vir gene expression (Morton et al. 2012). Therefore, after reaching OD600 at 0.7 in YMB medium the Agrobacterium cells were pelleted down and resuspended in Winans' AB medium. Tobacco leaf extract was added as a previously described (Rao et al. 2008) and such a way transient gus gene expression was increased significantly (Data not shown). In planta transformation method is relatively new and less explored than other tissue culture-based methods. Very few reports are available to date but all of them reported that vacuum infiltration treatment increases the efficacy of genetic transformation of Agrobacterium. In addition to Winans' AB medium and wounded tobacco leaf extract in the present study vacuum infiltration at different durations was employed to find out how much time led to the best transformation efficiency. It was found that $2 \mathrm{~min}$ of vacuum infiltration followed by $60 \mathrm{~min}$ of incubation period in Agrobacterium suspension yielded highest gus gene expression (Table 3). In case of in 
planta transformation of the de-coated half seed of black gram 2 min of vacuum infiltration is reported to enhance the genetic transformation efficacy to highest level though they have also used sonicator in combination with vacuum infiltration (Kapildev et al. 2016). Vacuum infiltration and sonication prior to incubation of explants in Agrobacterium suspension always enhance the T-DNA transformation efficacy (Kapildev et al. 2016, Yellisetty et al. 2015, Mayavan et al. 2013, Yadav et al. 2012).

Table 3. Effect of vacuum infiltration on genetic transformation efficiency.

\begin{tabular}{cccc}
\hline $\begin{array}{c}\text { Vacuum infiltration } \\
\text { duration (min.) }\end{array}$ & $\begin{array}{c}\text { No. of explants } \\
\text { assayed }\end{array}$ & $\begin{array}{c}\text { No. of explants showed } \\
\text { a positive response }\end{array}$ & $\begin{array}{c}\text { Percentage of GUS } \\
\text { positive explants }\end{array}$ \\
\hline 0.0 & 75 & 21 & 28 \\
0.5 & 75 & 27 & 36 \\
1 & 75 & 36 & 48 \\
2 & 75 & 39 & 52 \\
3 & 75 & 30 & 40 \\
4 & 75 & 18 & 24 \\
5 & 75 & 12 & 16 \\
\hline
\end{tabular}

The recalcitrant and genotype-specific nature towards in vitro regeneration and Agrobacterium-mediated genetic transformation of mungbean is an obstacle towards the genetic improvement of mungbean through genetic engineering. Moreover, due to the antibiotic selection the success rate droped drastically and in case to shoot regeneration and viable root formation in vitro. Mostly the success rate varies between 1 and $2 \%$ but the rate droped further during the acclimatization stage of the in vitro regenerated plantlets at environmental conditions (Bhajan et al. 2019). Therefore, in planta transformation could be an alternative option to produce healthy transgenic mungbean plants. This methodology has been proved more efficient in case of Vigna mungo (black gram) which is very closely related to mungbean (Kapildev et al. 2016). They have reported up to $46 \%$ positively transformed plantlets.

The present study clearly indicated that Agrobacterium-mediated in planta genetic transformation could be a better alternative towards the successful development of transgenic mungbean plants. The efficiency of the T-DNA transformation could be enhanced by using sonication in combination with vacuum infiltration. More efficient Agrobacterium tumefaciens strain and Ti-plasmid could also be used to enhance the transformation efficacy.

\section{Conclusion}

It is a preliminary experiment towards Agrobacterium-mediated in planta genetic transformation in mungbean. It is expected that it would inspire other researchers to conduct further experiments towards transgenic mungbean plant development using this technique. A proper in planta genetic transformation protocol for mungbean would 
eliminate the difficulties of in vitro regeneration step which is considered as the major obstacle towards the genetic engineering of mungbean.

\section{Acknowledgement}

Authors would like to thank the Bangladesh Agricultural Research Institute (BARI) for providing mungbean seeds. They also thank the University Grants Commission of Bangladesh, Agargaon, Dhaka-1207 for providing financial support through the University of Dhaka to carry out this work.

\section{References}

Baloda A and Madanpotra S (2017) Transformation of mungbean plants for salt and drought tolerance by introducing a gene for an osmoprotectant glycine betaine. J. Plant Stress Physiol. 3: 5-11.

Bhajan SK, Begum S, Islam MN, Hoque MI and Sarker RH (2019) In vitro regeneration and Agrobacterium-mediated genetic transformation of local varieties of mungbean (Vigna radiata (L). Wilczek). Plant Tissue Cult. \& Biotech. 29(1): 81-97.

Cheng M, Jarret RL, Li Z, Xing A and Demski JW (1996) Production of fertile transgenic peanut (Arachis hypogaea L.) plants using Agrobacterium tumefaciens. Plant Cell Rep. 15: 653-657.

Dewir YH, Murthy HN, Ammar MH, Alghamdi SS, Al-Suhaibani NA, Alsadon AA and Paek KY (2016) In vitro rooting of leguminous plants: Difficulties, alternatives, and strategies for improvement. Hortic. Environ. Biotechnol. 57(4): 311-322.

Faruq A and Islam M (2010) Field performance of nine mungbean varieties against three important diseases. Bangladesh J. Agric. and Environ. 6(1):77-84.

Himabindu Y, Reddy MC and Chandrasekhar T (2014) In vitro regeneration of green gram (Vigna radiata (L.) Wilczek) cultivar Vamban-2 using cotyledonary nodes. CIBTech J. Biotechnol. 3(4): 11-15.

Hoque M, Zahan MM and Sarker R (2007) In vitro plant regeneration in mungbean (Vigna radiata (L.) Wilczek). Plant Tissue Cult. \& Biotech. 17(2): 209-216.

Islam M and Islam K (2010) Agrobacterium-mediated genetic transformation of mungbean (Vigna radiata (L.) Wilczek). Plant Tissue Cult. \& Biotech. 20(2): 233-236.

Jaiwal PK, Kumari R, Ignacimuthu S, Potrykus I and Sautter C (2001) Agrobacterium tumefaciensmediated genetic transformation of mungbean (Vigna radiata $\mathrm{L}$. Wilczek) - A recalcitrant grain legume. Plant Sci. 161: 239-247.

Jefferson RA, Kavanagh TA and Bevan MW (1987) GUS fusions: beta-glucuronidase as a sensitive and versatile gene fusion marker in higher plants. EMBO J. 6(13): 3901-3907.

Kapildev G, Chinnathambi A, Sivanandhan G, Rajesh M, Vasudevan V, Mayavan S, Arun M, Jeyaraj M, Alharbi SA and Selvaraj N (2016) High-efficient Agrobacterium-mediated in planta transformation in black gram (Vigna mungo (L.) Hepper). Acta Physiol. Plant. 38: 205. 
Keshamma E, Rohini S, Rao K, Madhusudhan B and Kumar MU (2008) Tissue cultureindependent in planta transformation strategy: An Agrobacterium tumefaciens-mediated gene transfer method to overcome recalcitrance in cotton (Gossypium hirsutum L.). J. Cotton Sci. 12(3): 264-272.

Khatun M, Haque M, Islam S and Nasiruddin K (2008) In vitro regeneration of mungbean (Vigna radiata L.) from different explants. Prog. Agricul. 19: 13-19.

Kumar S, Kalita A, Srivastava R and Sahoo L (2017) Co-expression of Arabidopsis NHX1 and bar improves the tolerance to salinity, oxidative stress, and herbicide in transgenic mungbean. Fron. Plant Sci.8:1896.

Mayavan S, Subramanyam K, Arun M, Rajesh M, Dev GK, Sivanandhan G, Jaganath B, Manickavasagam M, Selvaraj N and Ganapathi A (2013) Agrobacterium tumefaciens-mediated in planta seed transformation strategy in sugarcane. Plant Cell Rep. 32: 1557-1574.

Mayavan S, Subramanyam K, Jaganath B, Sathish D, Manickavasagam M and Ganapathi A (2015) Agrobacterium-mediated in planta genetic transformation of sugarcane setts. Plant Cell Rep. 34: 1835-1848.

Mohanty I and Sagare D (2015) In vitro regeneration system in green gram (Vigna radiata L., Wilczek, cv. Sujata): a recalcitrant legume crop. Res. J. Agricul. Sci. 6(1): 64-67.

Morton ER and Fuqua C (2012) Laboratory maintenance of Agrobacterium. Curr. Protoc. Microbiol. 24(1): 3D.1.1-3D.1.6.

Niazian M, Noori SS, Galuszka P and Mortazavian SMM (2017) Tissue culture-based Agrobacterium-mediated and in planta transformation methods. Czech J. Genet. Plant Breed. 53: 133-143.

Rao KS, Sreevathsa R, Sharma PD, Keshamma E and Kumar UM (2008) In planta transformation of pigeon pea : A method to overcome recalcitrancy of the crop to regeneration in vitro. Physiol. Mol. Biol. Plants. 14(4): 321-328

Sahoo DP, Kumar S, Mishra S, Kobayashi Y, Panda SK and Sahoo L (2016) Enhanced salinity tolerance in transgenic mungbean overexpressing Arabidopsis antiporter (NHX1) gene. Mol. Breeding. 36: 144.

Saini R, Singh RP and Jaiwal PK (2007) Agrobacterium tumefaciens mediated transfer of Phaseolus vulgaris $\alpha$-amylase inhibitor-1 gene into mungbean Vigna radiata (L.) Wilczek using bar as selectable marker. Plant Cell Rep. 26: 187-198.

Samarajeewa D, Kottearachchi N and Jayawickrama C (2012) Transformation of tomato (Lycopersicon esculentum) by Agrobacterium tumefaciens using tobacco (Nicotiana tabacum) leaf extract. J. Food \& Agril. 2(2): 1-5.

Schafleitner R, Nair RM, Rathore A, Wang YW, Lin CY, Chu SH, Lin PY, Chang JC and Ebert AW (2015) The AVRDC - The world vegetable center mungbean (Vigna radiata) core and mini core collections. BMC Genomics 16: 344.

Tazeen S and Mirza B (2004) Factors affecting Agrobacterium tumefaciens mediated genetic transformation of Vigna radiata (L.) Wilczek. Pak. J. Bot. 36(4): 887-896.

Vats S, Solanki P and Alam A (2014) Efficient in vitro regeneration of Vigna radiata (L.) Wilczek. Researcher 6(1): 12-15.

Vijayan S and Kirti PB (2012) Mungbean plants expressing BjNPR1 exhibit enhanced resistance against the seedling rot pathogen, Rhizoctonia solani. Transgenic Res. 21(1): 193-200. 
Vir R, Lakhanpaul S, Malik S, Umdale S and Bhat KV (2016) Utilization of germplasm for the genetic improvement of mungbean [Vigna radiata (L.) Wilczek]: The constraints and the opportunities. In: Gene pool diversity and crop improvement: Volume 1, Rajpal VR, Rao SR \& Raina SN (eds). Springer International Publishing, Cham. pp. 367-391.

Winans SC, Kerstetter RA and Nester EW(1988) Transcriptional regulation of the virA and virG genes of Agrobacterium tumefaciens. J. Bacteriol. 170(9): 4047-4054.

Yadav S, Sreenu P, Maheswari M, Vanaja M and Venkateswarlu B (2010) Efficient shoot regeneration from double cotyledonary node explants of green gram [Vigna radiata (L.) Wilczek]. Indian J. Biotechnol. 9: 403-407.

Yadav SK, Katikala S, Yellisetty V, Kannepalle A, Narayana JL, Maddi V, Mandapaka M, Shanker AK, Bandi V and Bharadwaja KP (2012) Optimization of Agrobacterium mediated genetic transformation of cotyledonary node explants of Vigna radiata. Springer Plus 1: 59.

Yellisetty V, Reddy L and Mandapaka M (2015) In planta transformation of sorghum (Sorghum bicolor (L.) Moench) using TPS1 gene for enhancing tolerance to abiotic stresses. J. Genet. 94: 425-434.

(Manuscript received on 24 September, 2019; revised on 21 November, 2019) 